\title{
ENVIRONMENTAL INVESTMENT GOVERNANCE IN LATVIA: PLANNING PROCESS AND DECISION-MAKING FRAMEWORK DEVELOPMENT Zanda Krukle ${ }^{1}$, Ph.D.; Raimonds Ernsteins², Prof./Dr.habil.
}

1,2 Environmental Science Department, University of Latvia

\begin{abstract}
Applying governance process cycle steps model (5P model), the study focuses on the national environmental investment governance process by structuring and characterizing, particularly, investment planning process, including the integrative in-depth analysis of investment thematic content and framework (inextricably linked to the sectorial needs). Investment allocation is the governance instrument to be especially emphasized as being also necessary for the eventual implementation of all other governance instruments (such as infrastructure or communication ones), which all need financial support for their development, implementation or innovation. The study includes the investment instrument selection analysis at the policy planning stage for the most efficient investment and all sectorial policies implementation in order to reach the defined environmental governance goals. The study is practice-based research with elements of the participatory action research. Study is currently also topical since national investment planning process and final document is in the development process, detecting the main fields of investment in Latvia for the next 8 years. The structure and specifics of the planning stages of environmental investment governance process were identified along with related deficiencies and improvement needs, and, there were developed structured decision-making frame recommendation, based on the three main factors and subsequent set of complementary aspects identified as necessary required assistance to decide on the investment allocations.
\end{abstract}

Key words: EU investments, governance process, environmental governance, instruments.

JEL code: Q56, Q28, Q01

\section{Introduction}

In 2021, Latvia will celebrate 20 years since the first contracted European Union (hereinafter - EU) project has been signed. First investments became available in 2000, when Latvia benefited from EU pre-accession support (ISPA structural fund) for environment and transport sectors, but since 2004, when Latvia joined EU, Latvia has received funding from Cohesion fund, European Regional development fund, European Social fund (renamed as ESF+ fund), as well as Agricultural and Fishery funds. That means that Latvia has successfully finished 3 investment planning-management cycles and is currently under way with the implementation of 2014 - $2020 \mathrm{EU}$ funding period. Also, the newest 2021 - 2027 period has just started, however, the planning of it continues at both - EU and national level. Therefore, we assume that Latvian institutions that are working with the EU funds have gained long term experience on how to govern EU investments and use lessons learnt and best practices from their own experience, however, there seems to be space for further developments also taking into account, that EU investment governance has improved through new and strategic requirements, such as focused attention on intervention logic, climate, environmental tagging, fulfilment of enabling conditions (a.k.a. ex-ante conditionality) before the investments etc.

Currently the planning of new investments and the well-thought-out, sustainably done, integration of environmental and climate aspects into the planning of EU funds policy at the national level, is more important than ever, that is related to several aspects. First, new EU level planning documents have entered into force in recent years to address current issues and set the pathway to EU level and global climate, environmental and sustainability goals. For example, the EU Green Course has been adopted (which is, inter alia, in line with the Paris Agreement), with the aim of moving towards a climate-neutral, fair, and prosperous society with a modern, resource-efficient, and competitive economy. EU has also adopted sectoral documents such as the Biodiversity Strategy for 2030, the EU Circular Economy Action Plan, the

1 zanda.krukle@inbox.lv 
long-term low greenhouse gas emission development strategy, Renovation wave strategy etc., that draw the attention of Member States not only to existing but also emerging problems, which had not previously received adequate attention or were not properly identified or proven. Secondly, the Member States are currently planning financial resources for the 2021-2027 programming period, but, in response to the consequences of the COVID-19 crisis, EU offers additional resources for Member States to tackle social and economic challenges, while also respecting EU policy objectives, especially the EU-climate commitments (for instance, Recovery and Resilience facility, Just Transition fund and REACT-EU funding). This means not only the increase of available funding, which must be properly planned (considering the purpose, conditions, different timeframes of each mechanism and financial source), but also need for the complex and integrative policy (that also includes demarcation aspects), and balance between environmental protection and productive investments, and observation of the "do-not-significantly-harm" principle. The last, but not least, the implementation phase of the 2014-2020 planning period projects is currently still undergoing, therefore from 2021 to 2026, but especially from 2021 to 2023, there will be an overlap of several investments and programs.

In Latvia, the EU investments have helped to develop the main environmental infrastructure, such as water and wastewater networks and treatment plants, close old dumpsites and construct new environmentally safe landfills, create flood protection and NATURE 2000 infrastructure, recultivate historically polluted sites to protect nature and ensure favourable living environment in its holistic aspects. Also, investments in promotion and implementation of energy efficiency and renewable energy sources were supported to reduce greenhouse gas emissions. Nevertheless, each planning period has had its own indicators, that does not allow to provide correct summary of total results. Despite the multi milliard investments in the environmental sector, there are still unreached environmental acquis requirements or targets set in sectoral directives (such as those in waste sector - directives 1999/31/EC, 2018/850, 2008/98/EC, 2018/851 etc.), that might result with pilot cases or infringement procedures.

Due to the topicality of the issue, emphasising the importance of strategic and efficient planning of environmental investments, an analytic overview and analysis on how the environmental investment governance is currently ensured at the national level is needed, especially paying particular attention to the planning requirements and approaches at all governance process stages and instruments used. Therefore, the aim of the study was to explore, structure governance process and to frame the decisionmaking process as how the environmental investments are and are to be governed at the national level in Latvia (as EU member state). To reach the aim, several study tasks were selected: (1) through the appliance of environmental governance cycle model approach, to analyse how the environmental investments governance process is structured and succeeded; $(2)$ to explore how the use of governance instruments are planned and could be complementary developed; (3) to characterize deficiencies and strengths of Latvian EU investment governance process from problem analysis to planning stages and to propose framed decision-making improvements.

\section{Problem orientation: from theoretical aspects to practice in Latvia}

Cohesion policy (as a set of EU-level investment programs) is designed to help to reduce disparities between the levels of the development of the EU Member States and ensure the harmonious economic development and balanced growth of the EU. To reach this, EU funds tackle underdevelopment and enhance the growth both at EU and local level, especially by the tailor-made investment programs that fit to the needs of the region, also taking into account a different set of available resources (including tools/instruments) and external environment. It also requires wide networks and capable institutions to 
ensure long-term strategic development. These parameters are of utmost importance in the context of cohesion policy governance (Baltina and Muravska, 2014; Farole, et al. 2009). The Cohesion policy is a complex policy by its nature, design, and practical functioning in the contextual conditions (Basle, 2006). Cohesion Policy has a unified regulatory framework, but it must address different national and regional circumstances and institutional systems. It is comprised of a wide set of interventions and measures such as physical infrastructure and technology, innovation, business and digital developments, social inclusion and education, environmental improvement etc. that are allocated though different types of financial instruments, aid intensities, support measures and given to wide range of financial beneficiaries. (Basle, 2006)

Cohesion policy governance and planning (as an integral part of it) involves the goal setting that must be reached at the end of the seven-year planning period, as well as allocates necessary resources and sets activities that are needed to achieve the aim (Kooiman, 2008; Farole, et al. 2009). Cohesion policy over the years have become more target oriented and requires a strong intervention logic (i.e., characterization of thorough, efficient, and well-though-out comprehension on how proposed investments will lead to desired outcome), that are based on regional needs, analysis of disparities and underdevelopment, and goals that are set at regional, national and EU level. As the current programming phase demonstrates, the European Commission (hereinafter - EC) is demanding that objectives are specified with reference to results, realistic targets are set, enabling conditions (i.e., strategic sectoral documents as investment pre-conditions) are in place and the performance of the programs is properly monitored (Gorzelak, 2017) (European Parliament and Council, 2019 a, b).

To ensure efficient policy governance (especially for problem analysis and the development of the strategic framework), data and information must be gathered and analysed to gain sufficient evidence that can be used for decision-making and for ensuring planning capacity. The study of Baltina and Muravska (2017) shows that there is a strong need for high-quality and timely statistical data at all levels that represent correct data on actual situation. Information on previous investment is typically available only after the next planning period is started (due to overlapping of the planning periods), that hinders efficient decision making regarding new investments and future-oriented decisions, however, availability of data and knowledge is of utmost importance and requires a strong diagnostic element for the development of EU investment planning documents. Also, other authors (Crescenzi and Giua, 2017) agree that policymakers are obliged to decide on investment commitments, policy adjustments or reforms before they possess a long-term evaluation of the status quo and before the previous investment period is concluded, thus limiting the opportunities for practice learning.

Planning capacity and efficiency is also closely linked to setting up an appropriate institutional framework and cooperation between different sectors (Baltina and Muravska, 2017). This relates to the importance of stakeholder involvement from all five stakeholder groups (state institutions, residents, municipalities, enterprises, as well as mediators) to ensure adaptive environmental governance (Karpouzoglou et al., 2016; Ernsteins et al., 2017). This includes the organizational aspects of the interactions and participatory principles according to criterions of efficiency and effectiveness. When analysing environmental measures, some authors believe that the investments in this sector had various success. Some investments showed great effectiveness, such as for restoration and rehabilitation of polluted sites and water bodies. However, clean technologies projects were rather unsuccessful due to the lack of the capacity to promote these technologies effectively. Most regions had expertise in the restoration of derelict and polluted sites (Gorzelak, 2017). There was also a need for integrative and cooperation approaches for the mainstreaming 
of environmental and climate aspects within various sectors and with the involvement of stakeholders (Wamsler, 2017).

Baltina and Muravska (2017), analysing the situation in Latvia, consider that planning and prediction system in Latvia is not fully efficient yet. Bodies responsible for planning and implementation of EU funds in Latvia must better show the linkage between EU investments received and achieved Cohesion policy targets. There is also a need to search for better or new tools for data and evidence gathering to assess the efficiency and effects of the implemented policies on the development. The lack of proper interchange of data and information is detected both - at local and regional governance levels. There is also insufficient governance capacity along with uncertainties about the competencies of sectoral ministries. This may lead to the insufficiently coordinated actions and lack of compliance with the principle of transparency, that must be avoided.

\section{Research approach and methods}

Investments of the EU funds and structural funds, namely, investments of the Cohesion Fund and the European Regional and Development Fund in 2014-2020 and 2021-2027 programming periods in Latvia are analysed in this article. The environmental investment governance process is analysed applying management (policy/planning) process cycle model, particularly, using "5P stages" environmental governance process cycle model (Ernsteins, et al., 2017), tested for long in previous environmental, coastal, climate change, communication etc. governance studies. "5P stages" model includes all main consecutive cycle steps for any governance/planning process and, subsequently, stages are to be seen as inter-connected processes. "P1 stage" - problem analysis, "P2 stage" - policy design and formulation (strategic planning), "P3 stage" - planning, "P4 stage" - practice management (implementation), and "P5 stage" - process monitoring and reviewing of the results (Figure 1 ).

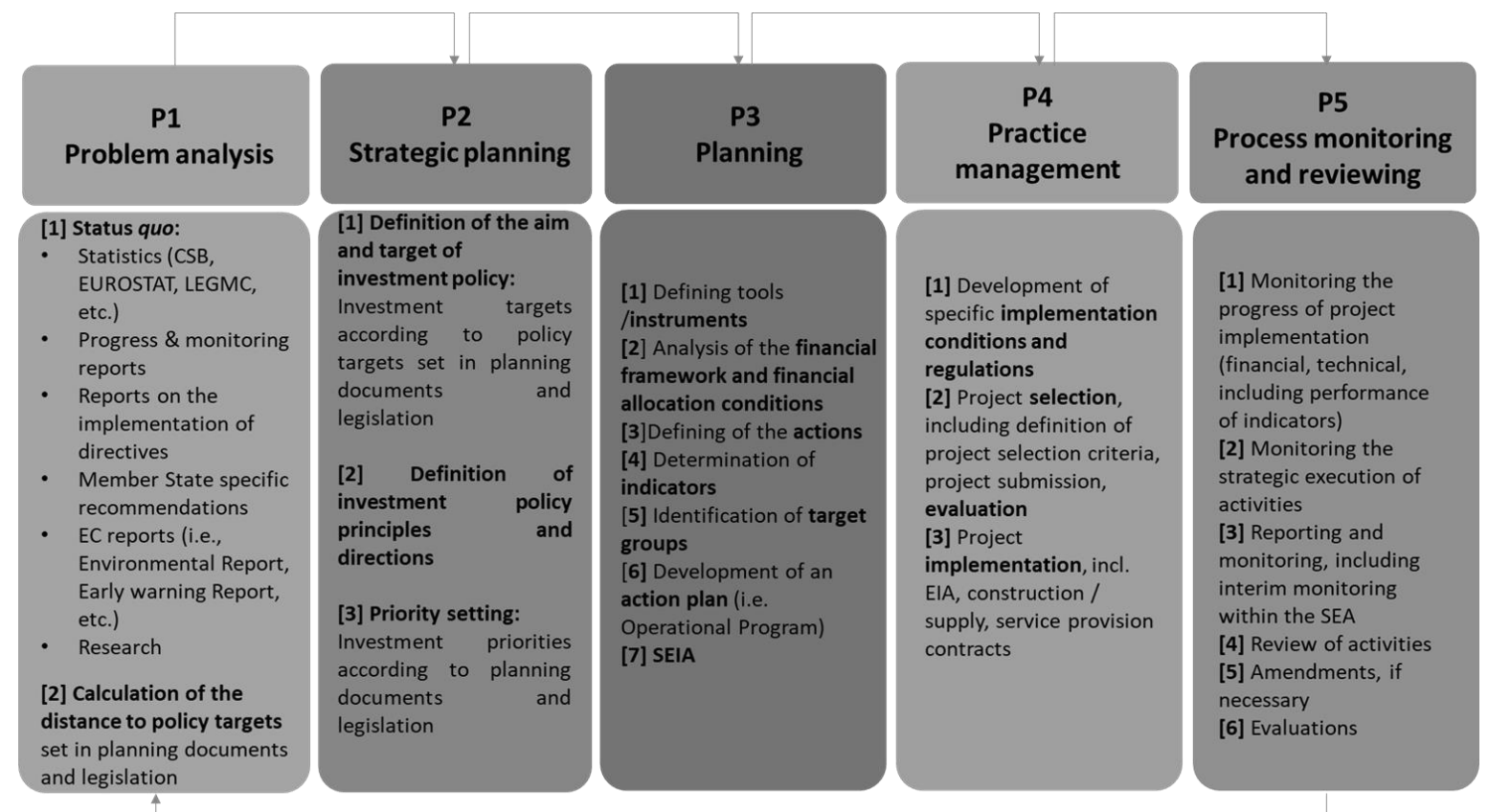

\section{Source: author's illustration based on Ernsteins, 2017}

\section{Fig. 1. Investment governance process stages in 5P model framework}

The investment governance process has been studied through a set of integrative and interlinked methods and/or their elements in the field of environmental governance. The study is practice led research that aims at analysis and development of new understandings and knowledge about investment governance 
practice (i.e., on means, processes, and results of the practice) of both - operational and scientific significance. As a crucial and integral part of the research is the practical knowledge on the topic, the authors employ their long-term knowledge and experience about strategical governance (practical planning and supervising of the implementation of these investments) and project level management in different environmental fields (i.e., water management, waste management and the circular economy, pollution management, adaptation to climate change, and biodiversity protection), that allows describing and analysing environmental investment planning activities and related processes in Latvia. The study employs research-and-development (R\&D) frame elements because the R\&D method allows producing a certain product (in this case - strategical investment documents) that inter alia allows describing the practice and test its effectiveness though the integrative appliance and analysis of investment governance cycle approach in this context.

The study process also includes the participatory action research elements realised within the Ministry of Environmental Protection and Regional Development of the Republic of Latvia (hereinafter - Ministry), in particular - Investment policy department. It was ensured though the collaboration with employees of the Ministry, who are fulfilling policy planning tasks and have their observations and reflections that are to be further used in decision making on investment governance. The participation was ensured thought the fulfilling the strategical investment programming and planning tasks for the preparation of the National planning documents (National development plan 2027 (hereinafter - NDP), National waste management plan 2028, Environmental policy guidelines 2027 etc.), EU investment planning documents, i.e., Operational Program 2027 and Partnership agreement 2027, as well as other background data documentation and their justifications. The engagement was ensured thought the sharing of the expertise and experience, that allowed to provide analysis and ensure sound decisions, taking into account also the experience and developed knowledge from previous 2004 - 2006, 2007 - 2013, 2014 - 2020 planning periods (regarding both - planning and factual implementation issues and best practices).

\section{Environmental investment governance frame: from EU level to the national level}

Environmental investment planning is ensured at 2 levels - EU and national level. The start of investment planning is marked with the first budgetary proposal of multiannual framework and draft regulations on EU funding (Common provision regulation and fund-specific regulations). The multiannual financial framework identifies available EU budgetary resources, including for structural and investments funds. Based on available financial resources and employing Cohesion policy funding allocation methodology (a.k.a. "Berlin methodology"), that considers various economic factors, such as gross domestic product, and additional premium payments of socio-economic and environmental criteria on top of the basic allocation, the available funding for each region/country is identified. EU regulations set main requirements for EU funding allocation. They define main investment directions (specific objectives), defines centralized indicators, require the fulfilment of the enabling conditions (national level horizontal and sectorial planning documents), set budgetary and time frames, including expenditure and reporting periods, requirements for sound administrative system, principles to be observed etc. (European Parliament and Council, 2019 a, b). They also define eligible and non-eligible costs (i.e., costs that can or cannot be funded using this financial support) that are in line with EU policy flagships, for instance, landfilling or fossilfuel reduction policies etc. Figure 2 illustrates the block-scheme of EU investment framework at EU and national levels. 


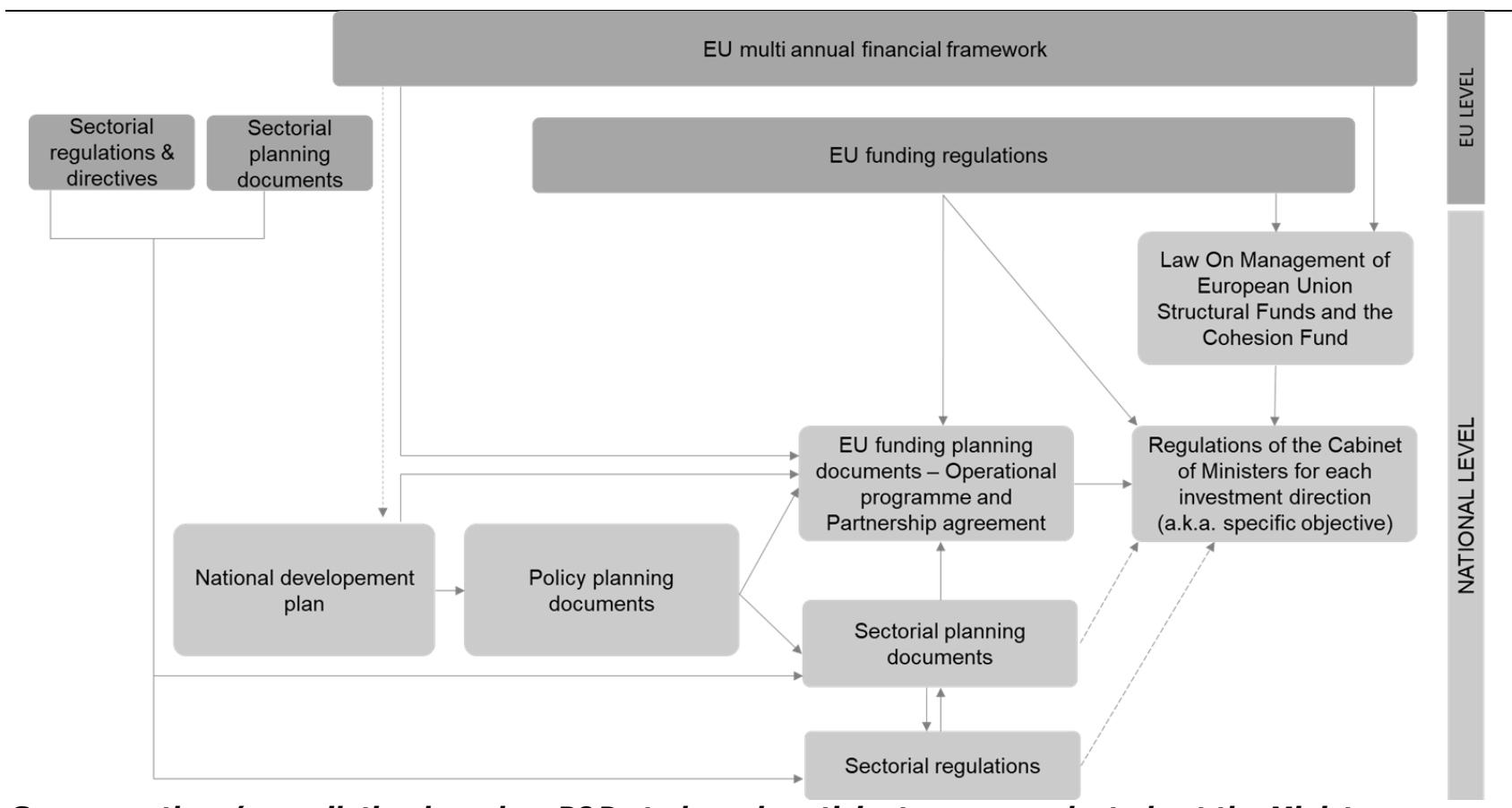

Source: authors' compilation based on R\&D study and participatory research study at the Ministry

Fig. 2. Block-scheme of EU investment framework: EU and national levels

Investment planning of EU funds at national level in Latvia begins with the development of the National Development Plan (NDP), which determines Latvia's development priorities for the coming seven years. Since the NDP is the main inter-sectoral development planning document in Latvia, it is the basis for future investment distribution. The NDP determines the directions of development and contains the main nationally important development tasks, as well as includes the distribution of planning investments for each task. The NDP is developed by the Cross-sectoral Coordination Centre at the Cabinet of Ministers, ensuring that line ministries identify, justify, and quantify the needs of the sectors under their responsibility. At the same time, it is acknowledged that the NDP is based on assumptions about the actual possibilities and potential investment portfolio of EU funds available to Latvia. Pursuant to the NDP, the investment proposal is expanded (i.e., gap analysis, investment proposals, territorial context and indicators, and other information is added) and included in the EU funds and structural funds main planning documents Operational Program and Partnership Agreement, which are developed in accordance with the form and requirements of the EU Funds common rules (European Parliament and Council, 2019 a, b). At the same time, the development of a list of issues for each area, specific investment support, target group, funding, indicators, relevant and climate objectives etc. must be proposed and justified. This is contextually and consecutively described and analysed in the next chapter on governance processes and stages.

\section{Environmental investment governance process in Latvia: analysis and planning stages}

EU environmental investments are planned for seven-year period, starting with the assessment of status quo (about one and a half to one year before the start of the programming period), definition of main policy directions and targets to be reached, and the implementation instruments, identification of the actions and the preparation of the action plan, as well as ensuring the involvement of social partners. EU investment governance process stages to be described below are seen in the 5P governance process model framework as illustrated in the Figure 1. 


\subsection{Investment governance process: problem analysis stage (P1)}

To prepare both - the NDP and the Operational program - the environmental investment planning process begins with data analysis, identifying the status quo in each investment area or sector to be analysed, for instance, showing data on the actual situation in different sectors - waste management, circular economy, climate change mitigation and adaptation to it, biodiversity, various forms of pollution, water management etc. For this purpose, statistical data (for example, from EUROSTAT, Central Statistical Bureau, Latvian Environment and Meteorology Centre database), progress and monitoring reports of various sectors, implementation of EU directives (for example, national level reports on the status of the Urban Wastewater Directive) are used. This allows identification not only of a snapshot of the existing situation, but also of current trends.

However, the quality of the analysis is much impacted by the availability and quality of data (for instance, data reported by sectoral enterprises). Data is also limited by the current report forms or are not available without specific studies (for instance, precise data on household heat combustion solutions), so some crucial data may not be collected at all. In that case, where possible and feasible, some special questionnaires are also made and distributed or evidence from scientific research is used.

Data and information from environmental assessment monitoring reports, progress and monitoring reports prepared by the EC (such as annual National policy implementation reports and fact sheets, early warning reports, country specific recommendations etc.), and the latest planning documents (for example, Waste management plan 2028, River basin management plan 2028, Air pollution abatement action plan etc.), as well as various surveys and studies are used for gathering and analysing the information on the sector and integrated problems and development needs is identified from the above-mentioned documents and data. For investment planning it is of utmost importance that these documents contain future trend analysis of the sector development. Good example in this respect is Waste management plan 2028 that includes several scenarios and projections of waste flows, that allows identification of future needs that is needed for sound and efficient planning of the sector and the implementation instruments. However, in many cases limited forecast data is available that impacts the identification of the investment gap.

The preparation of major sectoral planning documents often goes hand in hand with the investment planning period, that allows to use the most topical data available about the sector. Nevertheless, as the period of sectorial planning document preparation and investment planning is often overlapping, the investment programming is often started without full picture (because the planning document preparation has not been started or is in early stage). That means that the up-to-date data and prognosis may give new knowledge that could lead to new conclusions and to the re-assessment of the data and even the whole investment strategy or priorities.

These data are then analysed and compared with the data on the national, EU level and global goals and requirements of respective sector, especially those with set targets and deadlines. These data are gathered from extensive content analysis of the normative requirements (set in EU sectoral directives, regulations, national regulatory enactments, and international agreements) in the field of environment, as well as the set short-term and long-term goals (for example, landfill waste reduction to $10 \%$ by 2035 or achieving climate neutrality by 2050) in close cooperation with the Ministry's responsible line departments. The emphasis in the investment planning is put on the fulfilment of the EC requirements since EU funding is one of the instruments from EC to support Member States in the fulfilment of EU obligations. Data then are illustrated and analysed and put together in concise, but thoughtful illustration of the situation and its prognosis, that allows concluding on the main issues and gaps to the desired situation or goal, as well as 
to propose solutions to diminish problems and reach goal. This represents the main development gaps, that need to be solved, employing a set of governance instruments, that include also economic and financial instruments. To clearly communicate with society and EC and justify investment needs and intervention logic, illustrative materials that show the existing and potential distance to the targets are prepared.

The problem analysis done at the "P1 stage" will then be used for the decision taking on main gaps and will help to form the intentions, aims, principles, perspectives, and priorities at the "P2 stage". This analysis of "P1 stage" shows that the main bottlenecks are related to the availability of timely and qualitative status quo and future forecast data that limit development and investment gap analysis from todays and future perspective. To improve the data, the structural changes in data collection system, including well-thoughtthrough data reporting forms, preferably employing integrated solutions and ICT tools, is required along with the increased capacity of data quality controlling bodies. This allows to conclude that the authors agree with the analysis provided by Baltina and Muravska (2017) and other authors that there is an urgent need for data and evidence gathering and the improving of the governance capacity to improve efficiency of the analysis of existing policies and for the planning of new interventions. Meanwhile, the strengths are related to representation of the materials for the communication with stakeholder groups.

\subsection{Investment governance process: policy design and formulation stage (P2)}

In "P2 stage" policy orientation and definition takes place. This includes the setting of goals, particular targets main principles, as well as main priorities. Regarding environmental investment governance, "P2 stage" is closely linked with the goals set in the major sectorial policy planning documents (EU level and national level), and normative enactments in the integrative manner. As described, the identification of the targets set in these documents are scrutinized within the gap analysis provided in "P1 stage", and, since EU funding is a tool for the support of the fulfilment of EU requirements, the targets set in EU level documents, are binding also as EU investment aims. Meantime, considering that investment is only one of the instruments and the funding available is almost always insufficient to finance all factual sectorial needs, specific targets investment should be set. Usually targets to be reached are influenced by the EU predefined common investment outcome and result indicators, that impact the investment intervention logic. Targets are typically set considering the funding potentially available versus funding needed for the fulfilment of the target. This is done though the calculation of the costs of needed infrastructure (where possible, using calculation data from policy planning documents), and considering potential risks that might affect investment cost-efficiency or the fulfilment of the targets, such as inflation, previous investment uptake, historical data on market failures due to increased demand, negative demographic trends etc.

The environmental investment goals are also closely related also to the policy priorities, as investments should follow the sectoral development directions, supporting their implementation. However, if the planning document lack detailed description of priorities or principles of their identification or the up-todate planning document is under preparation, the investment might require preparation of separate sectorial evaluations that would set particular investment priorities. For instance, in 2020 separate water and wastewater investment evaluation was prepared that allowed setting priorities to detect the investment directions and targets in the sector. Meantime, through the involvement of social partners in the preparation of the planning documents or evaluations is critical, because investment activities, costs and priorities will greatly impact the investment plan (i.e., Operational program), because the plan has to be prepared in line with the sectorial planning documents to address their main needs, as well as it would help to lessen objections from social partners in EU funds monitoring committees and during the preparation of the legislation. 
The actions performed at the "P2 stage", i.e., set aims and targets, priorities, perspectives, and principles, in combination with the conclusions from "P1 stage" will then be used for the identification of main actions, development of the financial framework and setting of the indicators at the "P3 stage", and their inclusion in the planning document.

The strength of the existing practice is the strong investment linkage to the sectorial planning documents and targets. The main bottlenecks of "P2 stage" are interlinked the bottlenecks identified in "P1 stage", i.e., available data and redness of documents and overlapping of the preparation processes. The authors, therefore, also agree to the deficiencies described in the literature (Crescenzi and Giua, 2017) that policymakers base their investment decision before the previous investment period is finished, limiting the opportunities to prepare sound goal reaching and its risk analysis, that takes into account the factual fulfilment data of existing investment programs. Also, there is a risk, that the involvement of the social partner in the preparation of planning documents were insufficient or unsuccessful that would further impact the development of environmental investment plan.

\subsection{Investment governance process: planning stage ( $P 3)$}

After policy design and formulation stage, a specific investment implementation plan is developed. It is elaborated based on problem analysis, detected development gaps and needs (including the ones identified in the sectoral planning documents), and the priorities set. This also requires assessing the need for the use of whole set of environmental governance instruments, i.e., policy and legislative, planning, economic and financial, institutional, and administrative, infrastructure as well as communication (Ernsteins, et al., 2014; Ernsteins, et al., 2017) to guide the development of the field into desired direction. Once the appropriate instruments have been identified, specific proposals for supported actions are prepared, also evaluating which of potential support actions that will have the greatest impact of the identified sectorial and investment objectives and goals. Then the actions are assessed against the requirements of EU funds regulation and the development principles of the respective sector, and ineligible activities and costs are excluded (for instance, investments in waste disposal infrastructure, which is the lowest level at the waste hierarchy) (European Parliament and Council, 2019b). This sometimes requires re-designing of the activities for them to fit in the set investment framework. Then potential actions are brought to a practical level in main investment categories (such as construction, equipment, and service needs) and macro level cost breakdown is prepared. Also, the most appropriate output and result indicators are selected in line with the EU-level indicators already defined in the Fund specific regulations (European Parliament and Council, 2019b), which allow the determination and analysis of total investment intervention at EU and regional levels, summing data from all Member States. For the indicators baseline and target values are calculated or extrapolated from the available data (from data bases, policy documents etc.).

One of the issues in this planning stage is the fact, that investment needs in almost every sector is higher than available resources. Investment allocation per se is one of the main economic and financial instruments. At the same time, it is also a tool for the implementation of other instruments such as infrastructure or communication instruments, that need financial support. However, it is also often mistakenly believed that investment should be the main instrument for solving every sectoral issue. Therefore, it is crucial to determine, when investment as policy implementation tool must be used and is the best alternative. It is the state of the art on how to choose the right instrument, also taking into account that the decision taking must not be biased or lobbied.

To help decision takers, based on the research carried out, the Authors propose decision making framework for the investment allocation at the planning stage. It is described and summarized in the 
Table 1, the authors have identified three main factors and their 12 significant aspects that should be evaluated before choosing the investment as the most appropriate instrument. However, it should be also noted that there can be also other case specific factors. This framework is now used by the Ministry's experts to prepare proposals for investment to be included in the Operational program.

Table 1

Decision making framework development for the investment allocation

\begin{tabular}{|c|c|c|c|}
\hline Factors & Regulative/exclusion factor & $\begin{array}{l}\text { State aid and } \\
\text { Business-related } \\
\text { factor }\end{array}$ & $\begin{array}{l}\text { Factor of societal and } \\
\text { environmental interests }\end{array}$ \\
\hline \multirow{4}{*}{ Aspects } & $\begin{array}{l}\text { Additional / stimulation support (carrot) } \\
\text { should be, especially if there is new } \\
\text { regulations (stick) }\end{array}$ & $\begin{array}{l}\text { There is no } \\
\text { overstimulation of } \\
\text { business }\end{array}$ & $\begin{array}{l}\text { They are detected in other } \\
\text { policy planning documents }\end{array}$ \\
\hline & $\begin{array}{l}\text { There is a national, EU-level or global goal } \\
\text { and commitments that must be reached, } \\
\text { but the costs of reaching it are high }\end{array}$ & $\begin{array}{l}\text { Investment comply with } \\
\text { the state aid rules }\end{array}$ & $\begin{array}{l}\text { Investment needs do not } \\
\text { significantly harm the } \\
\text { environment (including the } \\
\text { future perspective) }\end{array}$ \\
\hline & $\begin{array}{l}\text { They are allowed in the Common provision } \\
\text { and fund specific regulations }\end{array}$ & $\begin{array}{l}\text { Market obstacles do not } \\
\text { allow to grant bank } \\
\text { support }\end{array}$ & It is needed for public interests \\
\hline & $\begin{array}{l}\text { There are demarcation, synergy with or } \\
\text { continuation of other support programs }\end{array}$ & $\begin{array}{l}\text { Support is not needed } \\
\text { for the operational costs }\end{array}$ & $\begin{array}{l}\text { Polluter pays principle is } \\
\text { observed }\end{array}$ \\
\hline
\end{tabular}

\section{Source: author's, based on R\&D study and participatory research study at the Ministry}

After all the above-mentioned work, the Operational program and related documents are drafted, including information on particular activities and their justification, financial allocations and indicators, and it is published for the public consultation with social partners. After public hearings of draft plan (that are to be held in accordance with the procedure for drafting planning documents), and multiple informal consultations with the EC on these documents, they will be submitted to the government, European fund's monitoring committee and EC for the approval.

In the next stages - practice management (P4) and process monitoring and reviewing of the results (P5) - investment legislation is prepared, projects are evaluated, approved and progress evaluated (i.e., regarding physical and financial indicators and policy results), and this is done in accordance to the works performed in the previous stages (i.e. set indicators, actions, instruments, costs etc.). If necessary, due to underperformance or unpredicted changes, the projects and/or investment plans can be reassessed and reviewed, starting this process again from the problem analysis (P1) (Figure 1). These two latest stages are highly impacted by the decisions taken in the previous stages, especially regarding on which activities, why and in which perspective they are chosen.

\section{Conclusions}

Employing analytic overview of the practices in place as well as structuration and principal characterization of the main stages of environmental investment governance process in Latvia, there are highlighted the main strengths and challenges of the first three process cycle stages (P1-P3) and, relatedly, proposed decision making frame for investment allocation.

1) There is not possible to provide strategic and structured outcomes summary of environmental investment governance process in Latvia due to the EU level investment governance practices improving over time by better tailor-made and focused requirements on intervention logics, new tools and unified indicators for all member states that helps to measure impact of the allocated funding. 
2) During the studies of problem analysis stage (P1) of the environmental investment governance process, there are several challenges recognized that relate to the availability of timely and qualitative status quo information and future forecast data that limits development and investment gap analysis from current and future perspective. To improve the data, the structural changes in data collection system are required, including increased capacity of data quality controlling bodies along with wellthought-through data reporting forms, preferably employing integrated solutions and ICT tools.

3) The main challenges recognized at the policy formulation stage (P2) were interlinked with those from previous stage, i.e., available data and readiness of documents and overlapping of the preparation processes. Also, policymakers shall make their investment decisions already before the previous investment period is finished, so limiting the opportunities to prepare sound and goal reaching policy formulation that considers the factual fulfilment data of existing investment programs. There is also to be mentioned eventual risk, that social partner involvement in the preparation of planning documents could be insufficient, impacting next stages.

4) In almost every environmental sector investment needs are higher than available financial resources and, consequently for the planning stage (P3), it is necessary not only to have sectorial and cross-sectorial knowledge, but also supporting algorithms to determine, when investment as policy implementation tool must be used and is the best alternative. Therefore, there is developed proposal for the decision making framework for the investment allocation that consists of three main factors to be considered - regulative/exclusion factor, state aid and business-related factor, as well as societal and environmental interests' factor, all covering altogether 12 aspects. After detection of investment actions, macro level cost breakdown, most appropriate output and result indicators, the Operational program and related documents are drafted, including information on particular activities and their justification, financial allocations and indicators, that is to be followed by public consultations with social partners that helps to finalize the final investment plan.

\section{Acknowledgements}

There are to be acknowledged the work practices studied of the Investment Policy Department of the Ministry of Environmental Protection and Regional Development.

\section{Bibliography}

1. Baltina, L., Muravska, T. (2017). What Institutional Arrangements Exist to Ensure Coherent EU Cohesion Policy Planning and Implementation? In Bachtler, J., et.al. (eds.) EU cohesion policy: reassessing performance and direction. New York: Routledge, pp. 271-284.

2. Basle, M. (2006). Strengths and Weaknesses of European Union Policy Evaluation Methods: Ex-Post Evaluation of Objective 2, 1994-99, Regional Studies, Volume 40. Issue 02, pp. 225-235.

3. Crescenzi, R., Giua, M. (2017). Different Approaches to The Analysis of EU Cohesion Policy: Leveraging Complementarities for Evidence-Based Policy Learning, In Bachtler, J., et.al. (eds.) EU cohesion policy: reassessing performance and direction. New York: Routledge, pp. 21-32.

4. Cross-sectoral Coordination Centre (2020). Latvia. National Development Plan 2021 - 2027.

5. Ernsteins R., Kudrenickis, I., Kaulins, J., Lontone-Ievina, A. (2017). Pro-Environmental Municipal Governance Developments in Latvia: Sustainability and Integration Principles in Practice. Proceedings, International Scientific Conference, VGTU, Vilnius, Lithuania, May 2017, pp. 308-317.

6. European Parliament and Council (2019a). Proposal for A Regulation of the European Parliament and of The Council Laying Down Common Provisions On the European Regional Development Fund et al.

7. European Parliament and Council (2019b). Proposal for A Regulation of the European Parliament and of The Council On the European Regional Development Fund and On the Cohesion Fund. Available:

8. Farole, T., Rodríguez-Pose, A., Storper, M. (2009). Cohesion Policy in the European Union: Growth, Geography, Institutions. Report "Reformed Cohesion Policy", London: London School of Economics

9. Gorzelak, G. (2017). Cohesion Policy and Regional Development, In Bachtler, J., et.al. (eds.) EU cohesion policy: reassessing performance and direction. New York: Routledge, pp. 33-54. 
10. Karpouzoglou T., Dewulf, A., Clark, J. (2016). Advancing Adaptive Governance of Social-Ecological Systems Through Theoretical Multiplicity, Environmental Science \& Policy. Volume 57. pp. 1-9.

11. Kooiman, J., Bavinck, M., Chuenpagdee, R., Mahon, R., Pullin, R. (2008). Interactive Governance and Governability: An Introduction. Journal of Transdisciplinary Environmental Studies. Volume 7. pp. 2-11.

12. Wamsler, C. (2017). Stakeholder Involvement in Strategic Adaptation Planning: Transdisciplinarity and CoProduction at Stake? Environmental Science and Policy, Issue 75, pp. 148-157. 